\title{
New or little known Palaearctic species of Platygastrinae (Hymenoptera: Platygastridae). II.
}

\author{
Peter Neerup Buhl
}

Buhl, P. N. 2005: New or little known Palaearctic species of Platygastrinae (Hymenoptera: Platygastridae). II. — Entomol. Fennica 16: 74-82.

Seven species new to science are described and their affinities discussed, viz. Anopedias notaulatus (Finland), Inostemma koponeni (Finland and Poland), Piestopleura canariensis (Canary Islands), Platygaster anopediana (Finland), P. oblonga (Finland), Synopeas bialowiezaensis (Poland), and S. discoideus (Finland). The males of Leptacis breisteini Buhl, 1997, L. coryphe Buhl, 1998, L. vlugi Buhl, 1997, Platygaster marttii Buhl, 2003, and Synopeas brevis Buhl, 1998, previously unknown to science, are described.

Peter Neerup Buhl, Troldhøjvej 3, DK-3310 Ølsted, Denmark; E-mail: pnbuhl@zmuc.ku.dk

Received 3 June 2004, accepted 10 September 2004

\section{Introduction}

This paper is a continuation of my previous paper (Buhl 2003). It treats material from a further loan by courtesy of Martti Koponen, this time comprising ca. 300 specimens of Western Palaearctic, mostly Finnish, Platygastridae. All material is deposited in the Department of Applied Biology, University of Helsinki (DABH).

\section{Species}

Anopedias notaulatus sp. n. (Fig. 1)

Type material. Holotype female: Finland (6855:365), Ta, Juupajoki, 3.VI.1987. Paratypes: Finland, N, Nurmijärvi, 1 female 16.VI.1991 (6707:378) and 1 male 2.VI.1992 (6705:379). All M. Koponen leg. and in DABH.

Diagnosis. An Anopedias with distinct and complete notauli.

Description. Female. Body length 1.4-1.5 $\mathrm{mm}$. Black, antennae and legs dark brown, both ends of tibiae and segments $1-4$ of tarsi lighter brown.

Head from above (Fig. 1a) 2.0 times as wide as long, hardly as wide as mesosoma; occiput reticulate-coriaceous, posteriorly partly smooth; vertex slightly transversely reticulate-coriaceous; frons smooth except for a few transverse wrinkles above antennae. OOL fully twice the diameter of lateral ocellus. Head in frontal view 1.1 times as wide as high; antenna (Fig. 1b) with A1 0.9 times as long as height of head, A9 1.3 times as long as wide.

Mesosoma 1.4 times as long as wide, 1.25 times as wide as high. Sides of pronotum reticulate-coriaceous in anterior corner, rest smooth. Mesoscutum with very few hairs except for a longitudinal row of deeply implanted hairs on lateral lobes, smooth except for some reticulation anteriorly of ends of notauli, these complete and strong, widely separated posteriorly, mid lobe very slightly prolonged to base of scutellum; scutoscutellar grooves only a narrow, bare line. Mesopleuron smooth. Scutellum smooth, flat, very 


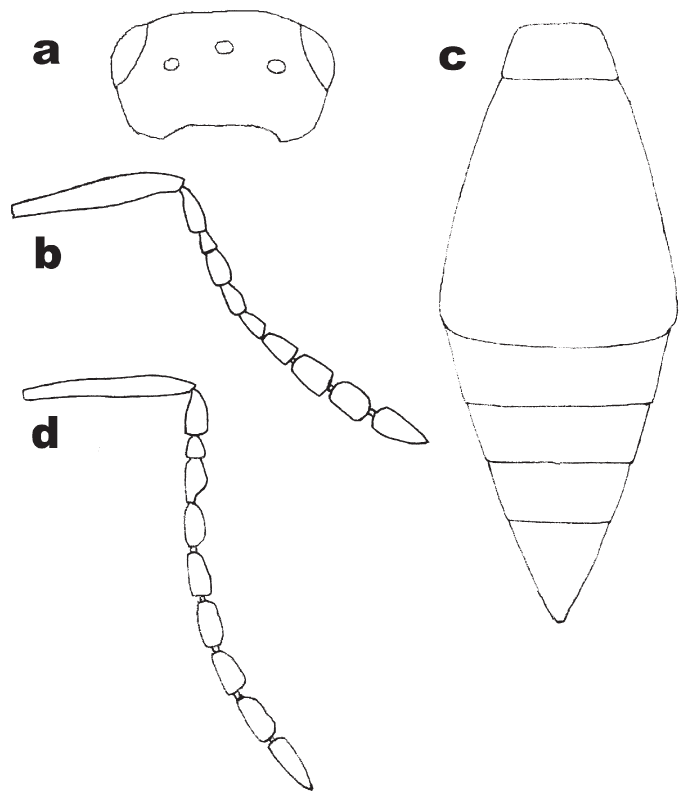

Fig. 1. Anopedias notaulatus sp. n., female (except d). - a. Head from above. - b. Antenna. - c. Metasoma from above. d. - Male antenna.

sparsely hairy. Metapleuron completely covered with pilosity. Propodeum with carinae parallel, and slightly transverse area between them smooth and shiny.

Forewing 0.8 times as long as body, 3.0 times as long as wide, with brownish tint and dense microtrichia; marginal cilia 0.1 width of wing. Hind wing 6.4 times as long as wide; marginal cilia 0.3 the width of wing.

Metasoma (Fig. 1c) 1.3 times as long as head and mesosoma combined, very slightly wider than mesosoma (21:20). T1 with two strong longitudinal keels, smooth between them, and hairy at their outer sides. T2 smooth, but hairy in anterior half of basal foveae. T3-T5 smooth, each with 2-3 superficially implanted hairs laterally; T6 smooth except for some small spots of rugosity, laterally with a few hairs.

Male. Body length $1.4 \mathrm{~mm}$. Antenna (Fig. 1d) with flagellar pubescence 0.75 times as long as width of segments. Metasoma 0.8 times as long as head and mesosoma combined.

Affinities. Generally similar to A. lacustris Kieffer, 1926 but this species lacks notauli and the metasoma of the female is shorter, cf. Huggert (1974). The only Anopedias apart from A. notaulatus with distinct notauli is the much smaller
West Indian species, A. conicus Ashmead, 1894, cf. Kieffer (1926).

Etymology. The name directs the attention to the distinct notauli, a characteristic feature of this species.

Inostemma koponeni sp. n. (Fig. 2)

Type material. Holotype female: Finland (6826:502), Sa, Ristiina, 20.VI.1986. Paratypes: 1 female, Finland (6825:623), K1, Parikkala, 30.VI.1990; 1 female, Finland (6653:354), N, Kirkkonummi, 25.VII.1991; 1 female, Poland, Poolasie, Bialowieza, 9.VII.1988; 1 female, Poland, Pomorze, Miastko distr., Stara Brda, 14.VII.1988. All M. Koponen leg. and in DABH.

Diagnosis. This species is distinct in having the vertex of the head evenly convex, A4 only

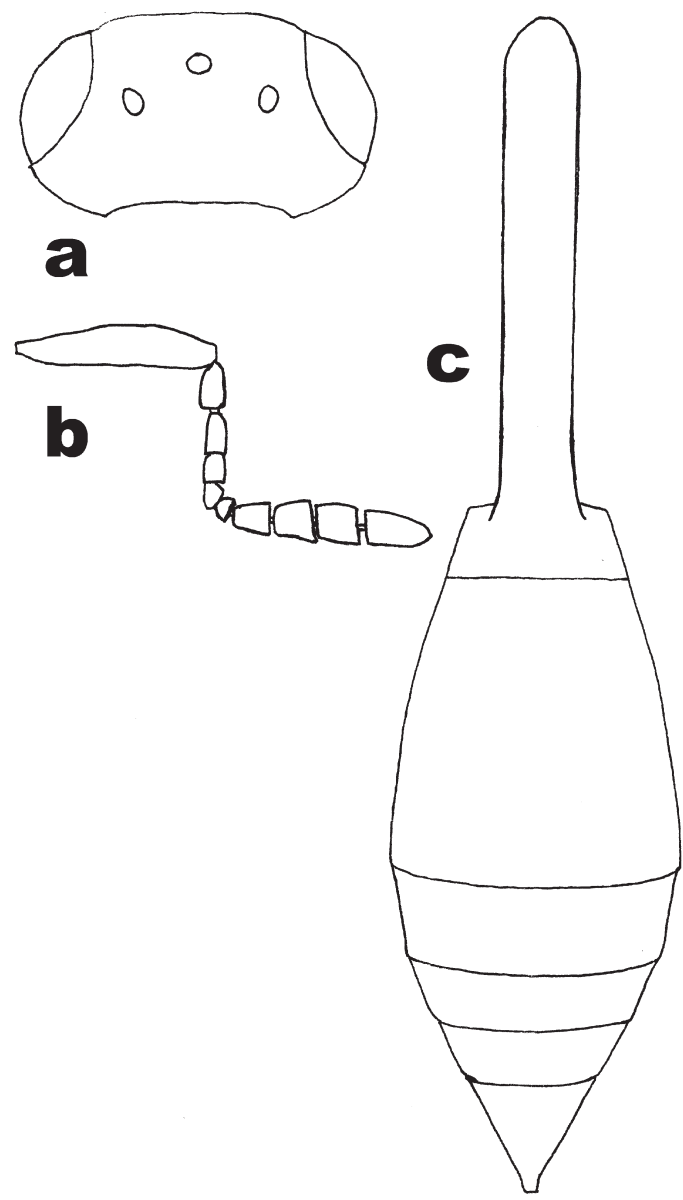

Fig. 2. Inostemma koponeni sp. n., female. - a. Head from above. - b. Antenna. - c. Metasoma from above. 
very slightly elongate in the female, and a $\mathrm{T} 1$ with a striated cornutus which reaches the anterior margin of mesoscutum.

Description. Female. Body length 1.5-1.7 $\mathrm{mm}$. Black; trochanters and both ends of mid and hind tibiae reddish brown; most of fore tibia and segments 1-4 of all tarsi yellowish brown.

Head from above (Fig. 2a) 1.7 times as wide as long, as wide as mesosoma across tegulae, finely and uniformly reticulate-coriaceous without transverse elements; vertex convex, without trace of notch; lateral ocellus as long as OOL. Antenna (Fig. 2b) with A3 1.8 times as long as wide, 1.5 times as long as $\mathrm{A} 4$ which is 1.2 times as long as wide.

Mesosoma 1.3 times as long as wide, nearly 1.3 times as wide as high. Sides of pronotum reticulate-coriaceous, smoother medially. Mesoscutum distinctly and uniformly reticulatecoriaceous, notauli complete but indistinct as they are shallow and sculptured as rest of disc. Mesopleuron reticulate-coriaceous, with longitudinal striations in posterior 0.5 in upper third, medially over most of length. Scutellum flat, sculptured as mesoscutum.

Forewing hardly reaching tip of metasoma, 2.3 times as long as wide, faintly infuscated, with fine and dense microtrichia and extremely short marginal cilia. Hind wing 4.5 times as long as wide; marginal cilia hardly 0.2 width of wing.

Metasoma (Fig. 2c) slightly more than 1.1 times as long as head and mesosoma combined (excluding cornutus), 0.9 times as wide as mesosoma. Cornutus of T1 somewhat irregulary longitudinally striated, reticulate near the base, just reaching the anterior margin of mesoscutum. T2 laterally striated to fully half of length, striations ending in longitudinal microsculpture which gradually becomes reticulate, rest of tergite distinctly reticulate, only antero-medially smoother. T3-T6 distinctly and uniformly reticulate, T3-T4 with numerous hairs laterally, T5-T6 covered evenly by numerous hairs; $\mathrm{T} 6$ as long as wide.

Male. Unknown.

Affinities. Similar to I. curtum Szelényi, 1938 but larger, with less slender basal flagellar segments, longer cornutus of T1, and more sculptured T2, cf. Szelényi (1938). Of the Mongolian Inostemma-species described by Buhl (in press),
I. koponeni is similar to three: I. intermedium differs from I. koponeni e.g. in having A8-A9 more elongate, I. kaszabi in having T2 smoother, and $I$. kerulense in having the head shaped differently.

Etymology. Named in honour of Martti Koponen.

Leptacis breisteini Buhl, 1997 (Fig. 3a)

Material examined. Type material described by Buhl (1997a). 1 male, Finland (6773:394), Ta, Lammi, 4.IX.1976, M. Koponen leg.

Description. Male: Length $1.1 \mathrm{~mm}$. Antenna (Fig. 3a) with A4 hardly widened, 1.5 times as long as A3; preapical segments each 2.0 times as long as wide; flagellar pubescence inconspicuous, A7-A9 each with a few longer hairs at apex. Scutellar spine with a lamella underneath along almost entire length. Metasoma hardly longer than mesosoma (27:25).
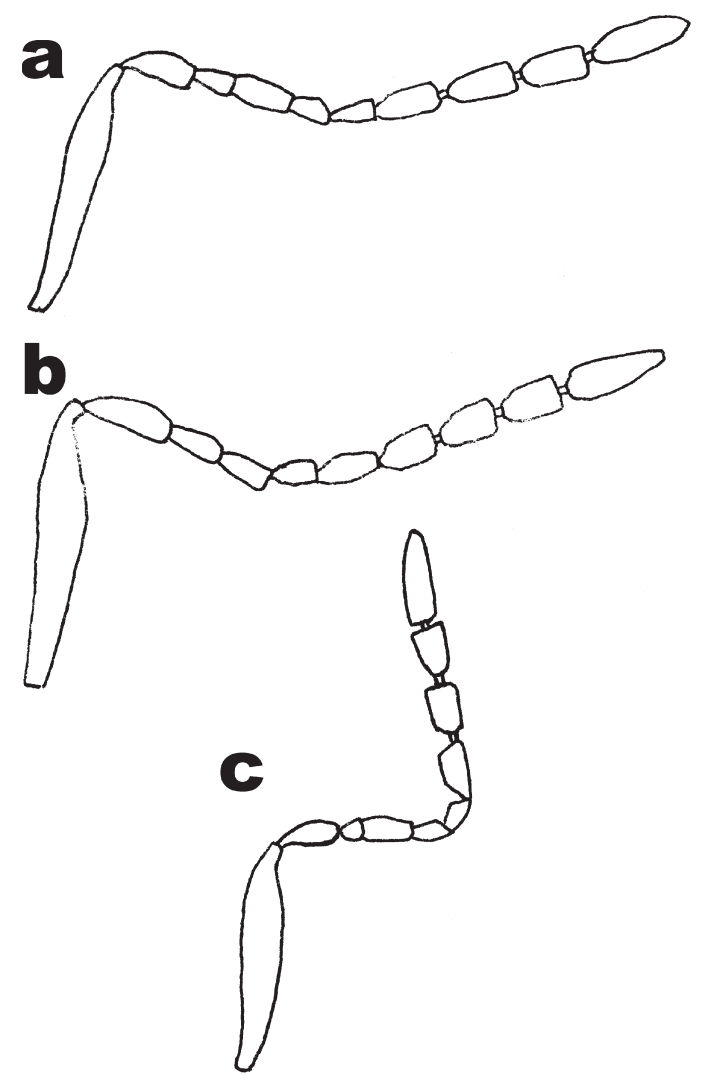

Fig. 3. Male antennae of Leptacis species. - a. $L$. breisteini Buhl, 1997. - b. L. coryphe Buhl, 1998. - c. L. vlugi Buhl, 1997. 
Affinities. Similar to L. ozines (Walker, 1835) in having strong notauli, but the males of the two species differ especially in shape of basal flagellar segments, in L. ozines A4 is distinctly widened and fully 3 times as long as A3, cf. Vlug (1985).

Comments. The male of this species is previously unknown.

\section{Leptacis coryphe Buhl, 1998 (Fig. 3b)}

Material examined. Type material described by Buhl (1998b). 2 males, Finland (6717:375), N, Nurmijärvi, 22.VIII.1991, M. Koponen leg.

Description. Male: Length $1.0 \mathrm{~mm}$. Antenna (Fig. 3b) with A4 unmodified; A7-A9 each 1.5 times as long as wide; flagellar pubescence fine and dense, half the with of segments; antenna almost uniformly light brown, width A1-A3 lightest. Metasoma as long as mesosoma.

Affinities. Easily separated from the related $L$. ariadne Buhl, 1999 in shape of antenna and scutellum, A4 being distinctly widened in $L$. ariadne which has scutellum more depressed and with shorter spine than in L. coryphe, cf. Buhl (1999).

Comments. The male of this species is previously unknown.

\section{Leptacis vlugi Buhl, 1997 (Fig. 3c)}

Material examined. Type material described by Buhl (1997b). 1 male, Finland (6706:382), N, Nurmijärvi, 25.VII.1986, M. Koponen leg.

Description. Male: Length $0.9 \mathrm{~mm}$. Antenna (Fig. 3c) with A4 slightly widened; A8-A9 each 1.4 times as long as wide; flagellar pubescence sparse and short with a few longer hairs at apex of A6-A9; antenna yellowish, A7-A10 dark brown.

Affinities. Differs from males of related species in having preapical antennal segments distinctly shorter, cf. Buhl (1999).

Comments. The male of this species is previously unknown.

Piestopleura canariensis sp. n. (Fig. 4)

Type material. Holotype female: Canary Islands, Tenerife, Puerto de La Cruz, Parque Tabro, 15.XI.2000, M. Koponen leg. and in DABH.

Diagnosis. A Piestopleura without a scutellar spine, with light yellowish brown scape and legs,

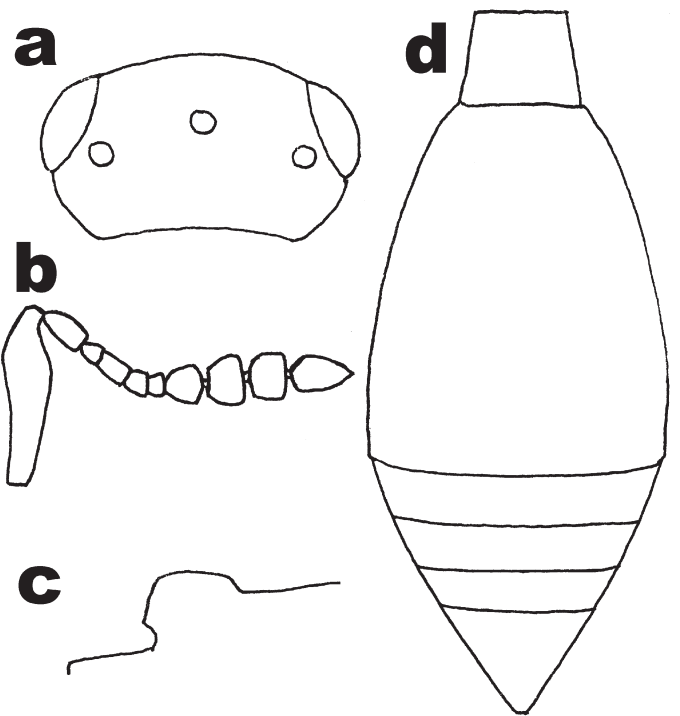

Fig. 4. Piestopleura canariensis sp. n., female. - a. Head from above. - b. Antenna. - c. Scutellum and propodeum. - d. Metasoma from above.

and the female metasoma not longer than head and mesosoma combined.

Description. Female. Body length $1.5 \mathrm{~mm}$. Black, A1 and legs light yellowish brown; A2A6 and coxae slightly darker; A7-A10 and last segment of tarsi dark brown.

Head from above (Fig. 4a) 2.0 times as wide as long, 1.4 times as wide as mesosoma, finely and almost uniformly weakly reticulate; lateral ocelli separated from eye by hardly half their diameter. Head in frontal view 1.2 times as wide as high; antenna (Fig. 4b) with A1 two-thirds as long as height of head.

Mesosoma 2.1 times as long as wide, 1.4 times as high as wide. Sides of pronotum with traces of longitudinal microsculpture in anterior half, rest smooth. Mesoscutum with sparse hairs, even finer microsculptured than head, without notauli; hind margin with a small, triangular prolongation medially, laterally with dense hairs. Mesopleuron with weak longitudinal striations below tegula, rest smooth. Scutellum (Fig. 4c) sculptured and hairy as mesoscutum, postero-laterally with dense hairs, unmodified posteriorly. Metapleuron smooth and bare in more than anterior half, rest with pilosity. Propodeal carinae dark, well separated, area between them smooth.

Forewing nearly reaching tip of metasoma, 
almost clear, 2.3 times as long as wide, with moderately dense, fine microtrichia; marginal cilia absent. Hind wing 5.3 times as long as wide; marginal cilia one-third the width of wing.

Metasoma (Fig. 4c) 2.4 times as long as wide, as long as head and mesosoma combined, 1.3 times as wide as mesosoma. T1 with two distinct longitudinal keels, smooth between them, laterally with hairs, antero-medially swollen. T2 laterally striated to 0.4 of length, medially smooth. T3-T5 almost smooth, T6 finely reticulate.

Male. Unknown.

Affinities. Similar to P. nievesi Buhl, 2001 (from central Spain), but with much shorter metasoma (1.5 times as long as head and mesosoma combined and 3.4 times as long as wide in $P$. nievesi), less slender forewings (2.9 times as long as wide in nievesi), and brighter colored body appendages (antennae and legs brown in nievesi), cf. Buhl (2001).

Etymology. Named after the Canary Islands.

\section{Platygaster anopediana sp. n. (Fig. 5)}

Type material. Holotype female: Finland (6950:622), Kb, Liperi, 4.VIII.1993, M. Koponen leg. and in DABH.

Diagnosis. A small Platygaster s. str. with broadly rounded, hardly striated occiput, preapical antennal segment of female 1.3 times as long as wide, slightly incomplete notauli, and mesoscutum and scutellum rather flattened dorsally.

Description. Female. Body length $1.2 \mathrm{~mm}$. Black, antennae and legs dark brown; both ends of tibiae and segments 1-4 of all tarsi yellowish brown.

Head from above (Fig. 5a) 1.8 times as wide as long, 1.2 times as wide as mesosoma; occiput finely transversely reticulate-striate; vertex reticulate; frons weakly fan-like reticulate from smooth midline. OOL $=1.4$ LOL. Antenna (Fig. $5 b)$.

Mesosoma 1.5 times as long as wide, 1.1 times as high as wide. Sides of pronotum longitudinally reticulate-coriaceous, smooth along hind margin. Mesoscutum with sparse hairs, weakly reticulate-coriaceous anteriorly, becoming smooth in posterior half; notauli fading out shortly before reaching anterior margin (absent in at most anterior 0.2 ), posteriorly meeting in a
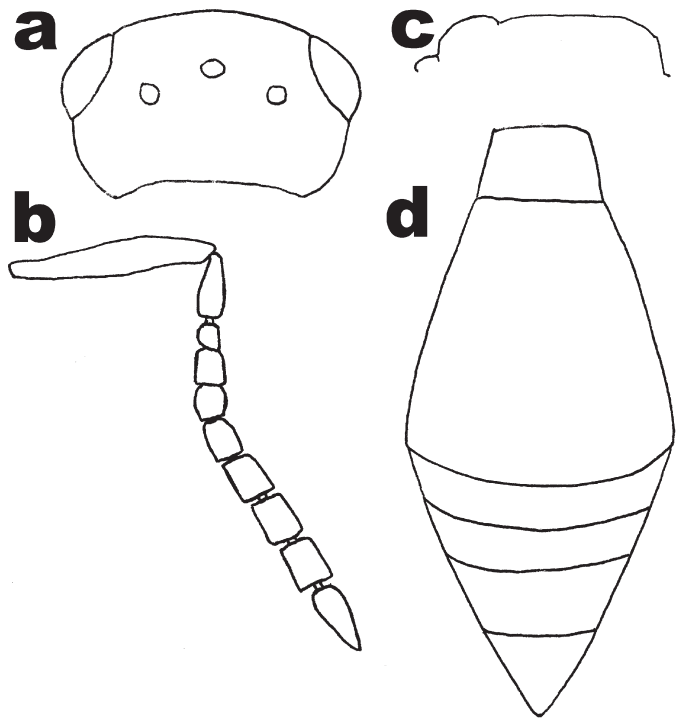

Fig.5. Platygaster anopediana sp. n., female. - a. Head from above. - b. Antenna. - c. Mesoscutum, scutellum and propodeum. - d. Metasoma from above.

rather narrow point which is slightly prolonged to base of scutellum; scuto-scutellar grooves rather narrow, with a few hairs. Mesopleuron smooth. Scutellum (Fig. 5c) very slightly above mesoscutum, faintly reticulate-coriaceous, moderately and evenly hairy. Metapleuron covered with pilosity. Propodeal carinae short, with a slightly sculptured, much transverse area between them.

Forewing 2.9 times as long as wide, with brownish tint and dense microtrichia; marginal cilia at their longest 0.1 width of wing. Hind wing 6.0 times as long as wide; marginal cilia one-third the width of wing.

Metasoma (Fig. 5d) hardly longer than head and mesosoma combined (17:16). T1 evenly crenulated. T2 striated from basal foveae to half of length, medially to 0.3 of length. T3-T5 smooth, each with a transverse row of superficially implanted hairs (medially interrupted on T3-T4); T6 not shiny, with scattered hairs.

Male. Unknown.

Affinities. This species belongs to the group (of small species with thick, not striated head and incomplete notauli) containing $P$. splendidula Ruthe, 1859 and P. picipes Förster, 1861, but it is stronger sculptured, has longer notauli, and has mesosoma more flattened dorsally than these species, approaching the shape of an Anopedias. 


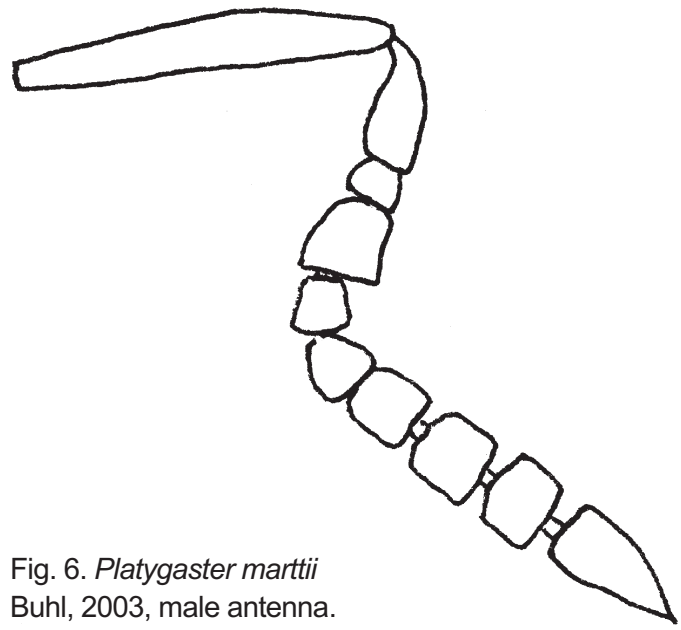

Etymology. The name refers to the somewhat Anopedias-like shape of mesosoma.

\section{Platygaster marttii Buhl, 2003 (Fig. 6)}

Material examined. Type material described by Buhl (2003). 1 female, 1 male in copula, Finland (6680:389), N, Helsinki, 5.VI.1986, M. Koponen leg.

Description. Male: Length $1.5 \mathrm{~mm}$. Antenna (Fig. 6) with A4 distinctly swollen, A7-A9 each hardly as long as wide; flagellar pubescence sparse, 0.25 width of segments; antenna uniformly blackish. Metasoma 1.1 times as long as head and mesosoma combined, T3-T7 combined 0.9 times as long as T2.

Affinities. Very similar to the male of $P$. attenuata Walker, 1835, cf. Vlug (1985), and to males of many other Platygaster-species which have the metasoma of the female elongate. At the present level of study, these species are separated only by differences of female morphology, especially antenna and metasoma.

Comments. The male of this species is previously unknown.

\section{Platygaster oblonga sp. n. (Fig. 7)}

Type material. Holotype female: Finland (6706:342), N, Nurmijärvi, 25.VII.1986, M. Koponen leg. and in DABH.

Diagnosis. Body very smooth, preapical antennal segments of female elongate, notauli strong, T4-T6 of female unusually long, without humped sternite 2 .
Description. Female. Body length $1.6 \mathrm{~mm}$. Shiny black; antennae, legs and T5-T6 dark brown; most of fore tibia, base of mid and hind tibiae, and segments $1-4$ of all tarsi yellowish brown.

Head from above (Fig. 7a) 2.0 times as wide as long, 1.1 times as wide as mesosoma; occiput smooth in posterior half, transversely striate-reticulate in anterior half; vertex transversely reticulate-coriaceous; frons smooth except for some faint, oblique striae from middle to around antennal insertions. OOL $=1.3 \mathrm{LOL}$. Head in frontal view 1.3 times as wide as high; antenna (Fig. 7b) with A1 hardly shorter than height of head; A9 1.2 times as long as wide.

Mesosoma 1.4 times as long as wide, 1.1 times as high as wide. Sides of pronotum smooth, with scattered hairs. Mesoscutum smooth except for reticulation along anterior ends of notauli and
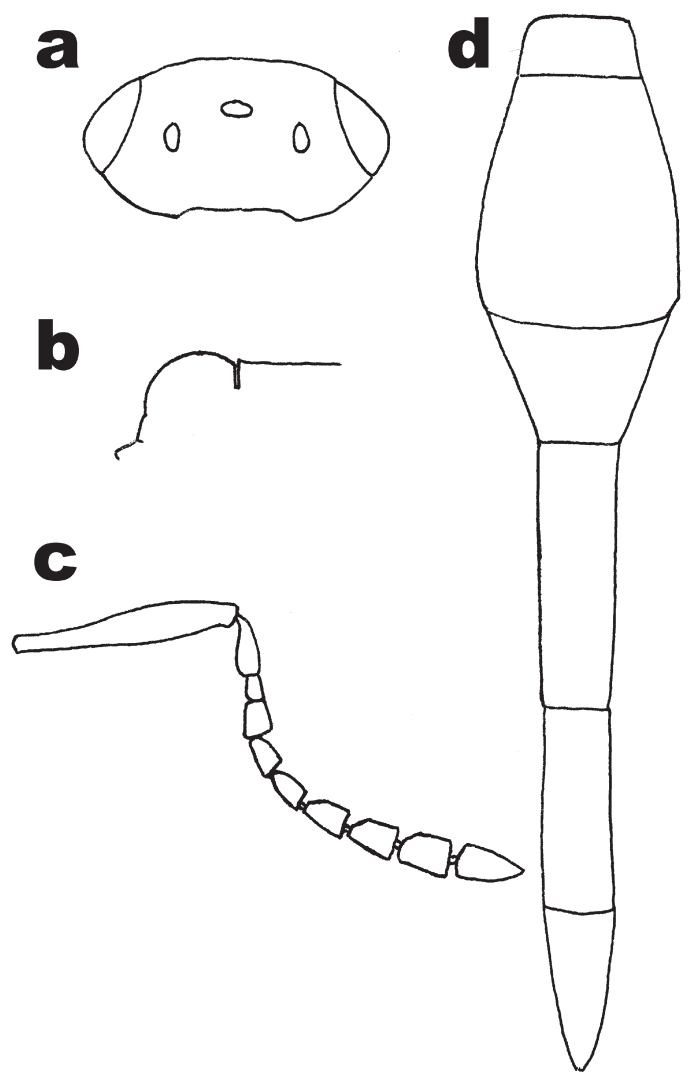

Fig. 7. Platygaster oblonga sp. n., female. - a. Head from above. - b. Antenna. - c. Scutellum and propodeum. - d. Metasoma from above. 
along anterior margin, bare except laterally and along notauli, these strong, abrupty ending just before reaching anterior margin, posteriorly widely separated, mid lobe only very slightly prolonged to base of scutellum; scuto-scutellar grooves each with about five long hairs. Mesopleuron smooth. Scutellum (Fig. 7c) smooth, with sparse hairs, evenly convex. Metapleuron covered with pilosity. Propodeal carinae very short, widely separated, much transverse area between them smooth.

Forewing 2.8 times as long as wide, reaching end of T5, clear, with dense microtrichia; marginal cilia at their longest 0.1 width of wing. Hind wing 6.0 times as long as wide; marginal cilia 0.25 width of wing.

Metasoma (Fig. 7d) 2.0 times as long as head and mesosoma combined, 0.8 times as wide as mesosoma. T1 smooth, with two strong longitudinal keels, only with a few hairs along sides. T2 striated in narrow basal foveae to 0.4 , rest of tergite as well as the following tergites smooth and bare. Sternite 2 without prolongation anteriorly.

Male. Unknown.

Affinities. Similar to P. cyrsilus Walker, 1835 but head less transverse, metasoma much longer with more constricted T3 and more parallel-sided $\mathrm{T} 4$, with more striated basal foveae of $\mathrm{T} 2$, and smoother between foveae than in P. cyrsilus, cf. Vlug (1985).

Etymology. The name refers to the relatively long metasoma.

\section{Synopeas bialowiezaensis sp. n. (Fig. 8)}

Type material. Holotype female: Poland, Poolasie, Bialowieza, 7.VII.1988, M. Koponen leg. and in DABH.

Diagnosis. A species with brightly colored body appendages, distinct scutellar spine, and transverse preapical flagellar segments, belonging to the species group characterised by having the mid lobe of mesoscutum prolonged as a smooth, roundish plate, clearly situated above level of scutellum, and by the convex metasoma.

Description. Female. Body length $1.4 \mathrm{~mm}$. Black, A1 and legs light brown; A2-A10, coxae and last segment of tarsi dark brown.

Head from above (Fig. 8a) 1.8 times as wide as long, 1.1 times as wide as mesosoma, finely and almost uniformly reticulate-coriaceous,

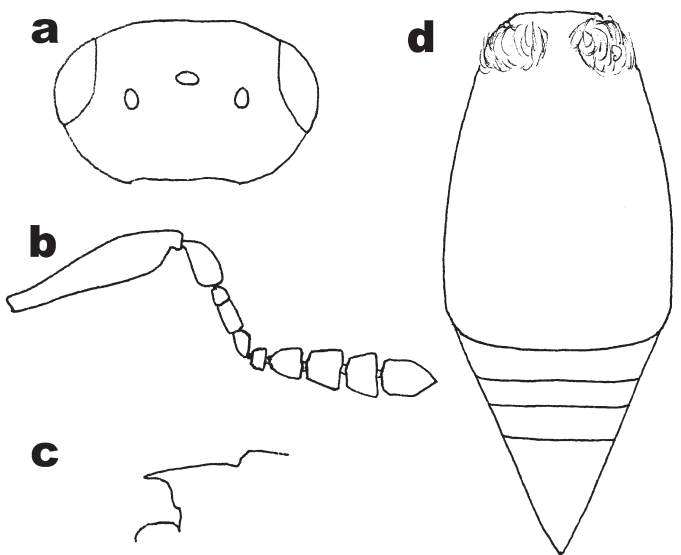

Fig. 8. Synopeas bialowiezaensis sp. n., female. - a. Head from above. - b. Antenna. - c. Scutellum and propodeum. $-\mathrm{d}$. Metasoma from above.

hardly transversely so; occiput without carina, only very feebly angled; OOL 2.3 times as long as diameter of lateral ocellus; LOL 1.1 times as long as OOL. Head in frontal view 1.1 times as wide as high; antenna (Fig. 8b) with A1 0.8 times as long as height of head.

Mesosoma 1.5 times as long as wide, fully 1.1 times as high as wide. Sides of pronotum finely reticulate in upper half, with weak longitudinal microsculpture in lower half, along hind margin smooth. Mesoscutum with numerous hairs, finely reticulate-coriaceous as head, without notauli, postero-medially somewhat prolonged, smooth and semitransparent brown above base of scutellum, along sides with dense, whitish hairs. Mesopleuron smooth. Scutellum (Fig. 8c) smooth and bare medially, laterally densely hairy, posteriorly with a distinct, semitransparent spine with a rather wide lamella below. Mesopleuron smooth and bare in about anterior 0.4 , rest with dense pilosity. Propodeal carinae slightly semitransparent, fused.

Forewing clear, 0.8 times as long as body, 2.7 times as long as wide, with fine and dense microtrichia; marginal cilia absent. Hind wing 6.1 times as long as wide; marginal cilia one-third the width of wing.

Metasoma (Fig. 8d) 1.1 times as long as head and mesosoma combined, slightly narrower than mesosoma, and slightly wider than high $(35: 33)$. T2 almost smooth, T3-T5 finely reticulatecoriaceous along hind margins, T6 with such 
sculpture all over except anteriorly; T3-T5 each with a transverse row of superficially implanted fine hairs (medially interrupted on T3-T4).

Male. Unknown.

Affinities. Differs from $S$. dravedensis Buhl, 2004 e.g. in structure of mesoscutum and scutellum, and in having lighter body appendages; from $S$. gibberosus Buhl, 1997 e.g. in having less elongate preapical flagellar segments and mesoscutum less swollen. Differs from the other related species around S. rhanis (Walker, 1835) in having more distinct scutellar spine and brightly coloured body appendages. Cf. Vlug (1985) and Buhl (1997b, 2004).

Etymology. The name refers to the type locality.

\section{Synopeas brevis Buhl, 1998 (Fig. 9)}

Material examined. Type material described by Buhl (1998a). 1 male, Finland (6705:378), N, Nurmijärvi, 24.VII.1992, M. Koponen leg.

Description. Male: Length $0.9 \mathrm{~mm}$. Antenna (Fig. 9) with A4 swollen; A8-A9 each 1.1 times as wide as long; flagellar pubescence distinct, 0.4 width of segments; A1-A4 yellow, A5-A10 brown. Metasoma hardly as long as mesosoma (23:24).

Affinities. Antenna slightly less slender than in male S. trebius (Walker, 1835), cf. Vlug (1985).

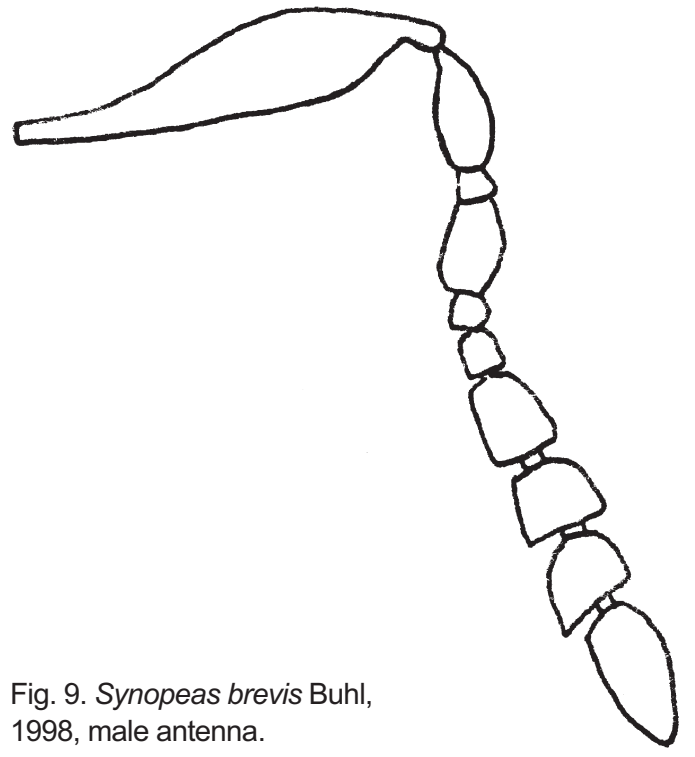

Comments. The male of this species is previously unknown. Due to colour of body appendages, pubescence of antennae and wings, etc., this is undoubtedly the male of $S$. brevis Buhl, 1998.

Synopeas discoideus sp. n. (Fig. 10)

Type material. Holotype female: Finland (6712:373), N, Nurmijärvi, 25.VII.1992, M. Koponen leg. and in DABH.

Diagnosis. A species with scutellum with only a minute tooth and slightly below the mesoscutum, and metasoma 1.5 times as high as wide with T6 nearly twice as long as wide.

Description. Female. Body length $1.7 \mathrm{~mm}$. Black, legs slightly lighter; segments $1-4$ of tarsi reddish brown.

Head from above (Fig. 10a) 2.0 times as wide as long, hardly wider than mesosoma, uniformly and distinctly reticulate-coriaceous without transverse elements; occiput smoothly rounded, without carina; OOL 1.6 times as long as lateral ocellus. Head in frontal view 1.25 times as wide as high; antenna (Fig. 10b) with A1 0.75 as long as height of head.

Mesosoma 1.3 times as long as wide, 1.1 times as high as wide. Sides of pronotum reticulate-coriaceous as the head, smooth in lower 0.25 and along hind margin. Mesoscutum with scattered hairs, finer reticulate-coriaceous than head, somewhat smoother but hardly lighter in front of scutellum; notauli absent; hind margin medially with a broad, roundish prolongation which slightly extends past the base of scutellum, laterally with numerous hairs above scuto-scutellar grooves. Mesopleuron smooth, dull just below tegula. Scutellum (Fig. 10c) slightly below mesoscutum, sculptured as mesoscutum, posterolaterally with dense hairs, posteriorly with a minute, dark tooth with a weakly semitransparent, narrow lamella below. Metapleuron smooth and bare in at least anterior third. Propodeal carinae short, curved, semitransparent, fused.

Forewing 2.7 times as long as wide, reaching about middle of T6, clear, with fine and rather dense microtrichia; marginal cilia absent. Hind wing 5.1 times as long as wide; marginal cilia hardly 0.2 width of wing.

Metasoma (Fig. 10d-e) 1.7 times as long as head and mesosoma combined, hardly 0.9 times as wide as mesosoma, 1.5 times as high as wide. 


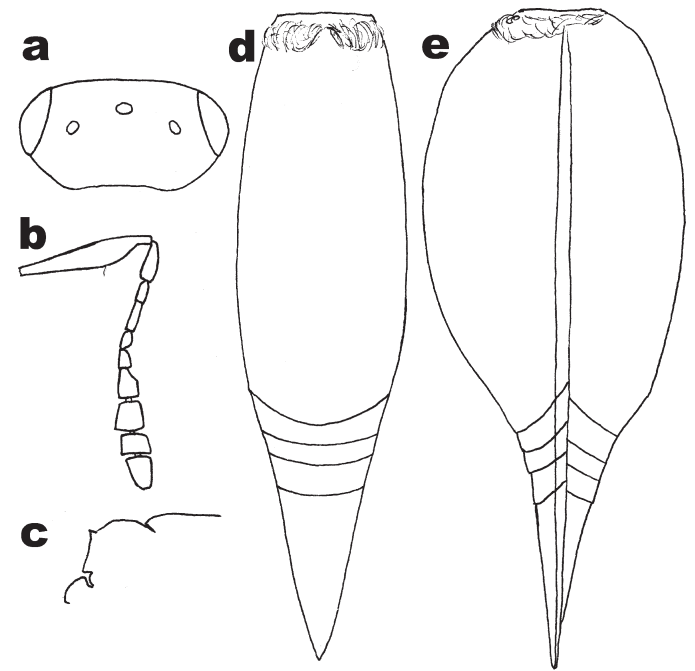

Fig. 10. S. discoideus sp. n., female. - a. Head from above. - b. Antenna. - c. Scutellum and propodeum. - d. Metasoma from above. - e. Metasoma in lateral view.

Hind margin of T2 and most of T3-T6 with fine reticulation; apical tergites with some fine hairs, forming a transverse row on T5. Sternite 2 in lateral view distinctly reticulate-coriaceous except in anterior 0.3 and along lower margin.

Male. Unknown.

Affinities. Close to S. hyllus (Walker, 1835) but metasoma more compressed and pointed, and scutellum differently shaped (lamella with indication of tooth stronger), cf. Vlug (1985).

Etymology. The name refers to the discshaped metasoma.

\section{References}

Buhl, P. N. 1997a: On six new or little known species of Platygastrinae (Hymenoptera: Platygastridae). Phegea 25: 107-115.

Buhl, P. N. 1997b: On some new or little known species of Platygastrinae (Hymenoptera, Platygastridae) . Entomofauna 18: 429-467.

Buhl, P. N. 1998a: Five new species of Platygastroidea from Norway (Hymenoptera). — Entomol. Fennica 8: 197-204.

Buhl, P. N. 1998b: On some new or little known NW European species of Platygastridae (Hymenoptera, Proctotrupoidea). - Fragmenta Ent. 30: 295-334.

Buhl, P. N. 1999: A synopsis of the Platygastridae of Fennoscandia and Denmark (Hymenoptera, Platygastroidea). - Entomofauna 20: 17-51.

Buhl, P. N. 2001: Ten new species of platygastrid wasps from central Spain (Hymenoptera, Platygastridae). Graellsia 57: 141-153.

Buhl, P. N. 2003: New or little known Palaearctic species of Platygastrinae (Hymenoptera: Platygastridae). Entomol. Fennica 14: 109-117.

Buhl, P. N. 2004: Ten new Palaearctic species of Platygastrinae (Hymenoptera, Platygastridae). — Entomofauna 25: 165-179.

Huggert, L. 1974: Revision of the European species of the genus Anopedias Förster (Hym. Proctotrupoidea, Platygastrinae). — Ent. Scand. 5: 277-288.

Kieffer, J. J. 1926: Hymenoptera Proctotrupoidea. Scelionidae. — In: Das Tierreich 48. Walter de Gruyter \& Co., Berlin \& Leipzig. 885 pp.

Szelényi, G. v. 1938: Über Paläarctische Scelioniden. I. Zur Systematik der Gattung Inostemma Walk. - Ann. Hist.-Nat. Mus. Hung., Pars Zoologica 31: 108-128.

Vlug, H.J. 1985: The types of Platygastridae (Hymenoptera, Scelionoidea) described by Haliday and Walker and preserved in the National Museum of Ireland and in the British Museum (Natural History). 2. Keys to species, redescriptions, synonymy. - Tijdschr. Ent. 127: 179-224. 